\title{
MARIAMA ON THE MOVE. CAPITAL MIGRATORIO Y SEGUNDAS GENERACIONES EN LA EMIGRACIÓN JUVENIL ESPAÑOLA
}

\section{MARIAMA ON THE MOVE. MIGRATION CAPITAL AND SECOND GENERATIONS IN SPANISH YOUTH EMIGRATION}

Laia Narciso y Sílvia CarRasco

Resumen: La representación mediática de las personas jóvenes españolas protagonistas de una nueva emigración hacia Europa en los últimos años suele recurrir, por defecto, a una composición homogeneizadora que no se corresponde con la realidad de este flujo. Este artículo contribuye a hacer visible la diversidad en la composición de los jóvenes españoles que emigran al extranjero en el contexto de crisis y sus estrategias específicas, a través del trabajo de campo etnográfico desarrollado en el área de Barcelona. El análisis se centra en el estudio de caso de Mariama, descendiente de migrantes de África occidental en Europa, y su movilidad comunitaria y de emancipación, que permite identificar la construcción y el uso del capital migratorio que subyace a la emergencia de un 'nuevo' proyecto de movilidad, sumándose a esa parte de la juventud española que se ha visto forzada a construir su futuro en otros países de Europa.

Palabras clave: movilidad transnacional; oportunidades educativas; jóvenes de origen negroafricano; emigración. 


\begin{abstract}
Media representations of Spanish young adults leading a new emigration wave towards Europe in the last years usually picture by default a homogeneous group that does not match with the real flow. This paper contributes to make visible the diverse composition of Spanish youth who migrate abroad in the context of the economic crisis and their specific strategies based on ethnographic fieldwork carried out in the area of Barcelona. The analysis focuses on the case study of Mariama, the daughter of a West African family who migrated to Europe, and her community and emancipation mobility. Her trajectory and experiences show how migration capital is built and used to produce the emergence of a 'new' mobility project, while she joins that share of young Spaniards who have been forced to build their future in other European countries.
\end{abstract}

Key words: transnational mobility; educational opportunities; youth of black African origin; emigration.

\title{
1. INTRODUCCIÓN
}

"Hablé con mi padre el año pasado para irme a Francia otra vez porque a mí ya no me gusta estar aquí", relataba Mariama. La situación económica familiar y las dificultades de inserción laboral fueron las principales motivaciones para plantearse la emigración, para estudiar y trabajar, como han hecho otros jóvenes españoles en los últimos años de recesión económica y altos índices de desempleo juvenil. Aunque su caso no era exactamente como el de otros jóvenes. Por una parte, contaba con experiencia previa de movilidad que le permitía comparar las condiciones de inclusión social en distintos contextos, y ser consciente de la desventaja que vivía la comunidad negroafricana ${ }^{1}$ en su lugar de residencia. Sentía, además, la falta de encaje con el grupo de iguales con el que había perdido la relación y veía limitadas sus aspiraciones educativas. Por otra parte, su

1 Descartamos el término "subsahariano" por tratarse de una denominación ajena al grupo estudiado, eurocéntrica y vinculada a una identidad impuesta y racista (Cabezas, 2005). Nos inclinamos por utilizar "negroafricano" al referirse a una de las fronteras visibles (Alba, 2005) que unifica a grupos diversos, y es más cercano a la auto-denominación más utilizada por los jóvenes durante el trabajo de campo, "negros", por encima de etnónimos de los diferentes grupos étnicos de África occidental (fula, sarahole, mandinga y wolof, entre otros) y nacionalidades (principalmente, Gambia y Senegal). 
propio habitus migratorio y el de su familia permitían considerar la emigración como uno de los proyectos posibles y frecuentes hacia la emancipación, como extensión del proyecto migratorio familiar y contando con la red transnacional de parientes.

Si en las estadísticas y los informes oficiales sobre emigración española los hijos e hijas de estos inmigrantes permanecen invisibles, en la escuela se habla de su "desaparición" que suele interpretarse como retorno (Narciso, 2010; Carrasco y Narciso, 2015). En el caso de los hijos e hijas de inmigrantes negroafricanos este tipo de movilidad ha teñido todo el debate, como si otros tipos de movilidad no fueran posibles para estos jóvenes. Replicando el título de la estrategia europea Youth on the Move (Horizonte, 2020) que pretende responder a los retos que afronta la juventud y promover su éxito en la sociedad del conocimiento apelando a los diferentes significados de la movilidad, se plantea aquí una doble contradicción: en primer lugar, se espera que los jóvenes se pongan "en movimiento" al tiempo que las condiciones para moverse se endurecen; en segundo lugar, se promueve en el discurso la movilidad europea pero genera suspicacias la que protagonizan personas en situación de mayor vulnerabilidad, limitando sus oportunidades educativas y sociales.

La perspectiva de análisis de la que partimos se basa en las aportaciones del paradigma de los regímenes de movilidad de (Glick Schiller y Salazar, 2013), que rompe con la dicotomía de la in/movilidad y tiene en cuenta el impacto de las desigualdades y los poderes globales sobre los individuos. En segundo lugar, se contemplan las aportaciones de los estudios sobre movilidad, educación y estrategias familiares ${ }^{2}$. Finalmente, siguiendo la epistemología del feminismo negro, se ha partido de las experiencias narradas por parte de las chicas y chicos y cómo se materializan las formas hegemónicas de poder discursivo y el privilegio en la vida cotidiana de estos jóvenes (Mirza, 2008).

Este artículo se organiza en tres partes. En la primera se contextualizan los debates sobre emigración española y sitúan la movilidad de las segundas generaciones de migrantes desde la óptica de análisis y la metodología de investigación desarrollada. La

2 Perspectiva desarrollada en el marco del proyecto MINECO, plan nacional I+D+I (2012-15) CSO 2012-34285 "La movilidad del alumnado y su impacto en la escolarización en la región metropolitana de Barcelona: tipos, procesos y tendencias". 
segunda parte se centra en el estudio de caso de Mariama a través de plantear y discutir las causas de la movilidad, las oportunidades educativas en distintos contextos y los impactos en las condiciones de emancipación. En la tercera y última parte, exponemos las conclusiones y proponemos el concepto de capital migratorio.

\subsection{La nueva emigración española y la juventud de origen inmigrante}

La idea de "la generación perdida" ha sido descrita por algunos autores como un fenómeno magnificado mediática y políticamente a la vez que desconocido. Paralelamente a la consolidación de España como país emisor de flujos migratorios, a partir de la crisis económica de 2008 y la posterior imposición de medidas de ajuste estructural en 2011 (Domingo, Sabaté y Ortega, 2014), se ha desarrollado un corpus de literatura científica que analiza las características de los procesos de emigración de población española nacida en España y/o en el extranjero. La inexactitud de los registros estadísticos ha impedido el manejo de cifras homogéneas e inequívocas, difuminando el conocimiento de este fenómeno y facilitando lecturas interesadas desde ámbitos como el político o el empresarial. Se ha construido una imagen homogénea de la nueva emigración joven española en términos de "fuga de cerebros" o "movilidad del talento", cuestionable ante la precariedad laboral y el subempleo como constantes del empleo juvenil en España (Santos Ortega, 2013).

Nos encontramos ante un fenómeno variado en el que tienen lugar migraciones cualificadas, de carácter menos condicionado (Gutekunst et al. 2016), que se producen junto a formas donde se impone la flexibilidad, a la vez que los protagonistas tienen o no relación con los flujos de inmigración internacional, en proyectos individuales pero también familiares. Entre los españoles nacidos en España destaca el grupo de edad de menores y ello se explica por la presencia de descendientes de migrantes, aunque no puedan distinguirse de los autóctonos en los datos (Domingo, Sabaté y Ortega, 2014; Domingo y Blanes, 2016). Esta composición diversa queda a menudo oculta en informes oficiales que sobredimensionan una pequeña parte del fenómeno y en cambio dejan fuera de estudio la población más vulnerable. Incluso las publicaciones que recogen esta diversidad se basan en supuestos preconcebidos, como que la emigración de tipo familiar es "con los padres" (Domingo y Blanes, 
2016), sin que se tenga en cuenta a los menores como agentes migratorios (Jiménez y Vacchiano, 2011), o bien la existencia de estrategias a través de las redes de cuidado transnacional (Merla, 2014) como, por ejemplo, las estancias con parientes en el caso la población de África occidental (Bledsoe, Houle y Sow, 2007) o, específicamente, los proyectos migratorios como estrategias de emancipación desde una perspectiva del ciclo vital (Wall y Bolzman, 2013).

En los apartados siguientes se analiza en profundidad un caso a través de dos tipologías de movilidad, comunitaria y de emancipación, que muestra las estrategias específicas de los jóvenes españoles hijos e hijas de inmigrantes hacia otros países europeos más ricos. En concreto, se persiguen los siguientes objetivos principales:

- Identificar y analizar la diversidad en la composición del flujo de jóvenes españoles que emigran al extranjero en el contexto de crisis y sus causas.

- Plantear el debate sobre el impacto de la movilidad en los jóvenes más vulnerables y, específicamente, en sus oportunidades educativas, como parte de las condiciones para la emancipación disponibles.

- Reconstruir algunas de las estrategias específicas y la movilización de capitales de los jóvenes españoles descendientes de migrantes de África occidental en Europa, que suelen pasar desapercibidas.

\subsection{Perspectiva teórica}

Este trabajo pretende superar el nacionalismo metodológico (Wimmer y Schiller, 2003) que naturaliza la definición de las unidades de análisis a partir de la frontera del Estado-nación y también el paradigma clásico de las migraciones basado en la perspectiva lineal origen-destino, partiendo de la teoría de los regímenes de movilidad (Glick Schiller y Salazar, 2013) que considera que las experiencias asociadas a las migraciones internacionales se sitúan fuera de la dicotomía in/movilidad y tiene en cuenta el impacto de las desigualdades y los poderes globales sobre los individuos. Movilidad e inmovilidad se definen recíprocamente y pertenecen a un marco global de relaciones desiguales, al tiempo que el contexto local específico — social, político, cultural y económico - resulta clave para comprender su complejidad. Además de centrar la atención en los sujetos que se desplazan, esta perspectiva propone incluir a todo 
el abanico de actores implicados, incluyendo al estado, y recupera la clase social como elemento clave en el acceso a un recurso diferencial como es viajar, valorado en los privilegiados pero cuestionado en los vulnerables (Glick Schiller y Salazar, 2013), una percepción que también se produce de forma clara en la movilidad escolar según el origen social y la condición de minoría (Carrasco y Narciso, 2015). Este enfoque permite comprender las distintas estrategias que despliegan las familias para responder a la precariedad y la discriminación con el objetivo de mantener el proyecto familiar de mejora de las condiciones de vida, con la red transnacional y el habitus migratorio como "nuevos" capitales.

Entre las teorías sobre procesos de incorporación de los migrantes que aplican una perspectiva estructural de reproducción social, los trabajos sobre comunidad étnica y lazos de solidaridad mostraron las ventajas de los sistemas étnicos de apoyo y control (Zhou, 2005) como un capital social beneficioso para superar condiciones desfavorables y desarrollar procesos de movilidad social ascendente. Aunque la presencia de redes sociales no se traduce siempre en capital social si no se dispone también de vínculos y redes sociales movilizables que permitan acceso a beneficios (Anthias, 2007). En este sentido, Putnam (2000) propuso la distinción entre redes sociales bonding o de unión de grupos homogéneos, que permiten reforzar identidades exclusivas pero protectoras, frente a redes de tipo bridging o puente, permitiendo múltiples identidades y acceso a grupos sociales con mayores recursos. Pero más allá de tipologías rígidas que corren el riesgo de resultar esencializadoras, el aspecto clave es que los vínculos étnicos conecten a personas con mayor acceso a recursos significativos, siendo menos útiles las relaciones entre grupos "uniformemente pobres" (Waters et al., 2010).

Las teorías sobre capital social resultan útiles para revelar relaciones no económicas que afectan a la posición en las estructuras sociales estratificadas, es decir, la posición de clase, pero esta perspectiva es insuficiente si no se articula con otras variables de estratificación social como el género y la etnicidad, de forma integrada o interseccional (Anthias, 2007). La aplicación de la perspectiva de la Critical Race Theory, que analiza el racismo y sus intersecciones con otras formas de subordinación, permite superar un enfoque de la comunidad étnica en términos de grupos estigmatizados (como los afrodescendientes en EEUU), alejarse de la perspectiva del déficit (Foley, 1997) e identificar formas alternativas 
de capital desconocidas y no-reconocidas (Yosso, 2005). Una de ellas es el concepto de habitus migratorio, inspirado en la cultura de la migración de Kandel y Massey (2002) y que ha sido desarrollado en España y, en general, en Europa desde el análisis de las movilidades y los procesos de adaptación de las comunidades de origen chino. En concreto, Masdeu y Sáiz (2017) describen prácticas de enculturación transnacional con o sin movilidad física de la generación menor. De forma similar, Nyíri (2014), desarrolló el concepto de transnational training refiriéndose al caso de los hijos e hijas de inmigrantes de origen chino en Hungría, y describiendo la educación de estos jóvenes para un mundo transnacional más que para ocupar una posición de minoría en la sociedad receptora. Otros autores también han analizado estos procesos de adquisición de capital vinculado a las migraciones en otros grupos de origen, como los polacos en Reino Unido y Alemania y la transferencia del habitus multicultural (Nowicka, 2015) o bien en relación con estrategias de clases medias, a través de conceptos como cosmopolitan capital (Weenink, 2008). Todas estas dimensiones nos ayudaran a comprender la trayectoria migratoria de Mariama.

\section{METODOLOGÍA}

Los datos analizados en este trabajo proceden de una etnografía multinivel (Ogbu, 1981) centrada en las experiencias y trayectorias vitales y académicas en un grupo de chicas y chicos de origen africano en un municipio costero de la provincia de Barcelona (de entre 20.000 y 30.000 habitantes) dedicado al sector servicios, fuertemente castigado por la crisis económica y con una tasa de paro en 2016 del 18,41\%, por encima de la media comarcal y autonómica. Desde los ochenta, pero especialmente en los noventa, llegaron al municipio inmigrantes de origen africano que iban a trabajar en el campo a los barrios en los que dos décadas antes que se habían establecido las migraciones procedentes de otras regiones del sur de España. Según datos del padrón municipal, en 2016 el 14\% de la población tenía nacionalidad extranjera y entre ellos destacaban los inmigrantes con nacionalidades del "Resto de África"3 (un 20,8\%)

3 Categoría demográfica que oculta la enorme diversidad del continente africano. 
siendo este origen el segundo en peso relativo, solo por detrás de "África del norte", unos porcentajes mucho más elevados que en la comarca y en la comunidad autónoma.

La investigación se ha centrado en dos grupos de jóvenes en distintos momentos del proceso de transición a la vida adulta, jóvenes-adolescentes y jóvenes-adultos, hijos e hijas de inmigrantes originarios de distintos países de África occidental, principalmente de Senegal y Gambia y, en concreto, de las zonas de origen en las que se realizaron diversas estancias ${ }^{4}$. Los datos sobre el grupo de jóvenes-adolescentes se han obtenido, en primer lugar, a través de observación participante y no participante durante un curso académico en uno de los tres institutos de secundaria públicos del municipio, con un seguimiento específico de cuatro grupos de $2^{\circ}$ de ESO. En segundo lugar, se profundizó en los perfiles de ocho menores de estos orígenes y sus redes de amistad, familiares y comunitarias a través de estudios de caso (cuatro chicas de segunda generación, un chico de primera generación, un chico de generación 1,5 y dos chicos de segunda generación), y de entrevistas con miembros del equipo directivo y psicopedagógico del instituto, entrevistas informales con el profesorado y grupos de discusión con los tutores y coordinadores de estos grupos. Los datos relativos al grupo de jóvenes-adultos se han obtenido a través de las reconstrucciones biográficas (Naples, 2003; Riessman, 2008) realizadas a 12 jóvenes (siete chicas y cinco chicos, todos de segunda generación) de 8 familias procedentes de países de África occidental pertenecientes al flujo que Jabardo (2006) llamó comunidades étnicas, complementadas con el análisis de sus perfiles públicos en las redes sociales y entrevistas en profundidad con algunos de los progenitores. En paralelo, se realizó observación participante en entornos y eventos familiares y comunitarios de la comunidad negroafricana de la zona de estudio, así como entrevistas formales e informales a distintos miembros de asociaciones negroafricanas del municipio y del área.

El análisis de los datos se ha realizado con el apoyo del programa de análisis cualitativo Nvivo. Todo el material ha sido transcrito, codificado en dos fases (generando indicadores de forma inductiva) y comparado a través de las herramientas visuales, las clasificaciones de caso y las matrices de análisis. Los datos incluidos y tratados

4 En la Upper River Division, de Gambia, y en la Región de Kolda, en Senegal. 
en los aparatados siguientes se basan en el estudio de un caso del segundo grupo de jóvenes (jóvenes-adultos) y, en concreto, en el caso paradigmático de Mariama.

\section{LAS EXPERIENCIAS DE MOVILIDAD DE MARIAMA}

Mariama es una chica negra de 21 años, que viste al estilo occidental siguiendo la moda mayoritaria entre las chicas de su edad, sin sobresalir, y no lleva velo aunque se define genéricamente como musulmana. En nuestro primer encuentro tenía 17 años y vivía, con su padre y su hermano cuatro años menor, tras el divorcio de sus padres. Nació en Cataluña, hija de padres senegaleses, de etnia fula. Con origen familiar de clase media en Senegal (la familia materna, abuelo contable y abuela comadrona, establecidos en la ciudad). En España, sus padres han ocupado trabajos poco cualificados (padre transportista y madre auxiliar de enfermería y ayudante de cocina en hoteles), aunque la madre dispone de estudios postobligatorios. En el momento de la entrevista se encontraban ambos en paro, siendo una de las familias afectadas por la deuda hipotecaria, y estaban acordando con el banco la dación en pago y el alquiler social. Esta situación contrastaba con su infancia, en la que, según ella, "siempre había tenido de todo". En la actualidad vive en Francia con familiares de su padre y con su hermano menor.

Toda su trayectoria vital se caracteriza por la movilidad. La primera infancia la vivió con su familia de origen (madre, padre y hermano) en un municipio costero de la provincia de Barcelona; su infancia, en una ciudad pequeña de la Provenza francesa, viviendo con parientes paternos; y el inicio de la adolescencia en la misma ciudad pero residiendo en otro barrio, con otros familiares. Durante su adolescencia volvió al mismo municipio donde pasó su primera infancia y en su juventud retornó a Francia, a la misma ciudad, pero con el apoyo de otros familiares paternos. En la tabla 1 se recogen los sucesos vitales destacados por ella misma (ver anexo $\mathrm{n}^{\circ} 1$, tabla 1 ).

Su primera experiencia de movilidad, a los ocho años, supuso para ella un importante cambio vital. Su percepción fue que iba a "vivir sola". Su relato destaca la soledad y la pérdida de relaciones importantes - la familia y los amigos-y apunta motivos educativos como principal causa de su estancia en el país vecino. 
"Muy bien hasta los ocho años que me fui a vivir a Francia, a vivir sola. Me llevaron allí para estudiar, no conocía a nadie, no conocía ni a mi familia ni nada, y fui allí y me quedé allí cinco años, y no estaba con mis padres ni nada."

Mariama "desapareció" de la escuela, no conocía los planes de su familia ni fue partícipe de la decisión de viajar cuando su familia la envió a Francia con parientes.

“...no sé, a lo mejor porque quisieron que aprendiera francés o que estudiara allí, porque... siempre les ha gustado Francia a ellos, y tengo muchísima familia allí y a lo mejor les aconsejaron que fuera allí para aprender francés, para tener un buen nivel de estudios, ya que el nivel de estudios de allí es más elevado que el de aquí."

En cambio, en el segundo episodio —su juventud-, parece tratarse de un deseo y decisión propios, que su padre acompañó, refiriéndose principalmente a oportunidades educativas y laborales y a un sentimiento de no-pertenencia. A continuación, analizaremos las dos principales hipótesis que emergen respecto a los motivos de su movilidad: una primera hipótesis vinculada a los capitales familiares disponibles y una segunda hipótesis como respuesta a la desigualdad y la discriminación experimentadas.

\subsection{El habitus migratorio como capital en los procesos de emancipación}

En una entrevista, el padre de Mariama explicó que su deseo era que su hija dominase el francés ya que es lengua oficial en Senegal. El aprendizaje del "segundo" idioma familiar podría considerarse, en el caso de los viajes al país de origen familiar, como un intento de acercamiento intergeneracional ante el miedo paterno a la aculturación, como apuntaban Farjas (2002), Gabrielli (2010) y Goldberg (2010). Según Mariama, su padre siempre quiso asegurar el dominio del idioma familiar (primero, fula y, segundo, francés) y, en general, de la cultura familiar, deseando que esté más "metida" o "involucrada" en ella —razones también aducidas por otras chicas del mismo origen.

"Sus raíces, su idioma, que este más metida, allí... yo, cuando hablo con él ¡siempre hablo en fula! Si se me escapa una palabra en español iya la he cagado! Sí, quiere que lo aprendamos absolutamente." 
El deseo de los padres de que sus hijos e hijas aprendan la lengua o lenguas familiares ha sido ampliamente documentado al analizar los procesos de incorporación de los hijos e hijas a la sociedad mayoritaria. También el mayor control y exigencia experimentados por las chicas de las segundas generaciones (horarios, compañías, regulación del cuerpo, participación en las tareas domésticas, religiosidad o dominio del idioma familiar, principalmente). Sus actos son interpelados de forma comunitaria, poniendo en cuestión la honorabilidad de su feminidad y, en última instancia, el prestigio familiar. Estos fenómenos han sido interpretados como parte de los procesos de resistencia comunitarios en contextos de incorporación hostiles para las familias, que presionan a las segundas generaciones hacia la asimilación cultural (Ajrouch, 2004; Bertran, Ponferrada y Pàmies, 2016). Sin embargo, en el caso de Mariama esta insistencia en la lengua no parece únicamente el intento de cerrar una brecha intergeneracional. Ella recordó la importancia del acento francés "de Francia", remarcando las diferencias del habla en cada región y el prestigio que tienen asociado.

"A ver, los negros cuando van allí, aunque sea colonización francesa y ya sepan hablar francés, el francés que hablan en Senegal o en Gambia y el que hablan en Francia no es lo mismo. Se nota mucho la diferencia si hablas francés de Senegal que si hablas... quiero decir, las palabras son las mismas pero el acento, la forma en la que hablan y tal..."

Así, el aprendizaje del francés en el habla de Francia puede entenderse también como una estrategia de movilización de capital social disponible en la red transnacional, en el contexto de un proyecto de mantenimiento o ascensión social que emprendieron las familias con la migración. Nos hallamos, pues, ante una estrategia de "enculturación transnacional" que emerge entre los grupos que tienen incorporada la cultura migratoria. Dominar el idioma familiar se convierte en un recurso, un capital, que acerca a los jóvenes no solo a sus progenitores y a la comunidad como enclave étnico, sino también a la red transnacional —en este caso, con una posición social más aventajada y un proceso de incorporación social muy anterior. Para Mariama, dominar el idioma familiar (fula) fue un recurso que le permitió comunicarse con sus tíos desde el primer momento de su llegada e incorporarse al nuevo núcleo familiar con mayor facilidad. La cultura migratoria también se ha consolidado 
en África occidental. Sow (2007) afirmó que las migraciones formaban parte de la vida política, social y económica, y suponían un fenómeno inseparable de la vida de los individuos. Además, en África occidental la movilidad temporal con parientes se considera una experiencia de vida positiva para los hijos (Bledsoe, Houle y Sow, 2007), al mismo tiempo que ofrecer hospitalidad a los visitantes (o "acoger extranjeros" expresión literal escuchada en el trabajo de campo) era un elemento clave para desarrollar una honorable identidad como mujer adulta del grupo (Kaplan, 1998). Desde esta perspectiva, se comprende la normalidad que supone para muchos padres "enviar" a los hijos e hijas a realizar estancias con parientes y las razones nada aleatorias que la sustentan, trasladando de forma transnacional una red de cuidado femenina disponible aunque, como explicó Mariama, este no sea siempre un rol deseado y pueda convertirse en una obligación que recae en las mujeres, aspecto que ocasionó discusiones continuas en el primer domicilio francés donde residió.

En conclusión, el habitus migratorio y los capitales que puede poner en juego la movilidad transnacional son elementos clave de las motivaciones para delegar la crianza en parientes, una estrategia educativa que desarrollan las familias negroafricanas para promover la movilidad social de los hijos e hijas, manteniendo y afianzando los objetivos de su proyecto migratorio. Además, facilita la emergencia de proyectos migratorios propios de los hijos e hijas, que pueden emprender su emancipación a nivel transnacional, ante situaciones adversas.

\subsection{La movilidad como estrategia para afrontar la desigualdad y la discriminación experimentadas}

El relato de Mariama revela un segundo argumento importante que sustenta la movilidad, especialmente la de tipo emancipatorio, que decide y emprende por sí misma en su juventud, apoyándose también en la red familiar transnacional. Un ejemplo claro de ello es que, antes de viajar, su tío consultó qué estudios podía realizar ella allí con sus títulos españoles. Ella explicó que quería volver a Francia porque "ya no le gusta estar aquí". La complicada situación económica familiar y las dificultades de inserción laboral que tienen los jóvenes en España fueron las principales motivaciones para 
plantearse un nuevo proyecto migratorio una vez finalizados los estudios superiores. Pero no se refiere a esas cuestiones directamente sino a una incomodidad incorporada, a un sentimiento de desagrado que podemos traducir como los efectos de la experiencia del racismo, la sensación creciente de no pertenencia a un lugar. En su relato percibimos cierta idealización de Francia, insistiendo en que "hay más educación" (aludiendo al hecho de que en la escuela se dirigen a los profesores por el apellido), mayor nivel de estudios y menos tiempo dedicado al ocio nocturno, así como más empleo. En su discurso, además, suele enlazar estos indicadores —el nivel educativo o el empleo- con la experiencia de racismo sentida, es decir, la intersección entre clase social y color. "Hay más racismo aquí", afirma, en un contexto en el que está arraigada la ideología racial color-blind, que sustenta el mito de la no-racialización y niega o minimiza las experiencias de racismo (Bonilla-Silva, 2006). A pesar de ello, los elementos que aporta no van más allá de los ejemplos clásicos de racismo en el espacio público, como el hecho de sentirse juzgada por estar en grupo —en un grupo de jóvenes negros y negras- en el tren.

Aun así, es posible que estas percepciones estuvieran menos acentuadas en Francia, donde al parecer sus parientes habían conseguido establecerse con cierta estabilidad desde generaciones anteriores, pero también ante los niveles reales de inclusión social y comunitaria y el reflejo social recibido (Suárez-Orozco y SuárezOrozco, 2003), específico en cada contexto. A Mariama, la movilidad le sirvió para evidenciar estas dos cuestiones y resistirse a normalizar la falta de presencia de personas negras en entornos mayoritarios, o la falta de referentes de éxito.

"Yo, de los años que he estado aquí no he visto nunca a un conductor negro, marroquí o indio o lo que sea... siempre han sido españoles blancos... pero allí mi tío, tengo un tío que es conductor de autobús. Tengo mi tío que ha estado ocho años en la universidad y es ingeniero químico y es profesor en la universidad y trabaja en un laboratorio de esto y tal...(...) yo aquí no he visto nunca un negro que llegara tan lejos...jno sé!”

Sin embargo, aunque Mariama verbalice más claramente el racismo sentido, reproduce discursos de la ideología color-blind como la meritocracia que justifica el privilegio blanco, y el blaming the victim. Por ejemplo, ella critica un supuesto "poco esfuerzo de 
integración" de las primeras generaciones de migrantes en España, lamentándose de su baja competencia en español, o de la "falta de actitud para incorporar tradiciones y fiestas" del lugar en el que se instalaron. Se aprecia una interiorización del discurso público hegemónico sobre integración que destaca el esfuerzo personal y unidireccional, sin tener en cuenta el contexto.

“¡Es que llevan veinticinco años o más y ya ves! ¡Que mi padre no habla bien español! y muchos negros no lo hablan bien, no se les entiende casi... para mí eso es un poco de vergüenza ¿no? (...) ¡la mitad son muy cerraos! De que yo hablo mi idioma y ya está, me relaciono con esta gente y ya está... no hacen las fiestas... y ¡uno se tiene que acostumbrar aquí!”

La crítica a la comunidad negra de esa zona de Barcelona le permite distanciarse de una red comunitaria que no la favorece, e intentar incorporarse a otra - la francesa- que le ofrece mayores oportunidades orientadas hacia una emancipación inclusiva, según su percepción. En resumen, esta nueva movilidad podría ser una estrategia propia, de emancipación, nutriéndose de la red transnacional para afrontar la discriminación y la desigualdad de oportunidades experimentada por la comunidad negroafricana en España. Se trataría de diferentes estrategias ante la misma situación que los padres de chicos y chicas que promovían retornos a origen pretendían afrontar (Bledsoe y Sow, 2011). Así pues, parece que es posible identificar las causas de la movilidad como estrategias que pretenden promover mejores condiciones hacia la emancipación (educativa y de inserción laboral, especialmente) y facilitar la movilidad social ascendente, manteniendo el principal propósito del proyecto migratorio familiar desde que se planteó en la generación anterior.

\section{OPORTUNIDADES EDUCATIVAS EN DOS CONTEXTOS: CONTINUIDADES Y CONTRASTES EN LOS FACTORES DE VINCULACIÓN SOCIAL Y ESCOLAR}

El itinerario académico de Mariama se desarrolló entre el sistema educativo español y el francés. Cursó educación infantil y parte de primaria en un municipio de la provincia de Barcelona, finalizó primaria y realizó el primer curso de secundaria en una 
ciudad pequeña de Francia, volvió para terminar la secundaria en el mismo municipio donde pasó su primera infancia y realizó un Ciclo Formativo de Grado Medio de Gestión Administrativa y, por último, retornó a Francia, con planes de continuar los estudios y/o trabajar. Finalmente, sabemos que optó por cursar Bachillerato (Lycée). Siempre asistió a escuelas e institutos públicos, que según ella se parecían en muchos aspectos. En las entrevistas realizadas no explicó si existió algún tipo de seguimiento o transferencia de información entre centros educativos. Sus relatos muestran una alta vinculación académica y social en su escolarización en Francia, en contraste con su experiencia en España. En su trayectoria es relevante el descenso de rendimiento académico al regresar a España, en la etapa de educación secundaria.

En los dos apartados siguientes se analizarán las distintas formas de apoyo escolar y educativo que se identifican en su trayectoria y que pudieron contribuir a generar altas aspiraciones educativas, y superar las barreras encontradas, para mantenerlas y llevarlas a cabo.

\subsection{El apoyo escolar desde el ámbito familiar y comunitario}

En su relato, Mariama insiste con afecto en las altas expectativas educativas de su padre hacia ella, que siempre le transmitió y materializó aportado los recursos necesarios para su continuidad educativa.

"Siempre, siempre. Él está encantado ¿sabes? Él siempre está: me da igual lo que me tenga que gastar, si quieres esto lo harás. Si son estudios, claro, porqué es por mi futuro, por mí; por mis padres, también."

A diferencia del desinterés que suele atribuirse a las familias de origen inmigrante sobre la continuidad educativa de las hijas, este es un caso en que la familia transmitía un discurso de aprovechamiento escolar y de confianza en la escuela como vehículo para la movilidad social. Dentro de sus posibilidades, el padre realizó una inversión en educación como parte de los objetivos del proyecto migratorio familiar y este discurso contribuyó a establecer unas altas aspiraciones educativas. Pero Mariama no nombró otros apoyos que pudieran haber generado sus aspiraciones o ayudado a mantenerlas. En cambio, en Francia encontró en las hijas de su 
tío un apoyo efectivo para la rápida adquisición del nuevo idioma y ayuda directa en las tareas escolares.

En su narrativa podemos apreciar la existencia de distintos estilos parentales más o menos pro-académicos. Probablemente, la supervisión que realizaron sus familiares franceses, con hijas mayores que ya habían pasado por el sistema educativo y lo conocían mejor, también encajaba mejor con el comportamiento y los valores escolares en general. En cambio, la etapa en la que se encontraban sus padres en España, migrantes pioneros estableciéndose e invirtiendo la mayor parte de las horas en trabajo (Gabrielli, 2010), produjo cierta ausencia de supervisión parental. Como ella misma explicó: en Francia "iba del cole a casa" mientras que en España "ni volvía a casa" y empezó el ocio nocturno y todo lo que ello implica, muy joven (por ejemplo, volviendo a los trece años a casa de madrugada). Todo ello se sumó posteriormente a la separación de los progenitores, pasando ella a desempeñar el rol de mujer adulta de la casa a los 17 años.

"Sí, yo... se me hacía más fácil allí, tal vez allí me sentaba más a hacer los deberes, volvía del cole, merendaba y hacia los deberes siempre. Aquí volvía del cole, dejaba la mochila y me iba para la calle... O si no ja veces ni volvía a casa!"

Otro factor relevante en el contexto francés, ya señalado anteriormente, fue la existencia de referentes y modelos de éxito en su red de parientes (familiares con estudios, tío profesor) que contribuían a generar en ella una identidad pro-académica.

"Sí, la que iba a la universidad [prima] era la que me ayudaba más. Me ayudaba mucho. No sé, recuerdo que cuando fui de vacaciones a Francia me decían "¡Eras muy buena en el cole! Te aplicabas mucho", y tal."

Este elemento pudo ser clave para potenciar altas expectativas educativas aunque en su relato Mariama no establezca esta relación causa-efecto de forma consciente.

\subsection{La experiencia escolar positiva}

Mariama recordaba a algunos profesores que fueron figuras clave que le apoyaron en su escolarización primaria en Francia facilitando su incorporación y una experiencia escolar satisfactoria. 
“Tenía una profesora muy buena, que hablaba un poco de español ¡el director también me cogió mucho cariño, y todo! No sé, yo creo que como que me vieron tan perdida, que no sabía nada y tal, pues siempre estaba con ellos allí... muy muy majos. (...) A veces hasta en los exámenes cuando le preguntaba ¡me decía más de la cuenta!"

Sin embargo, de España recordaba los mensajes del profesorado en los que atribuían algunos malos resultados académicos únicamente a su actitud ("no quieres"), responsabilizándola sin tener en cuenta su historia personal, ni prever ningún apoyo.

"Yo me dije, ¡como que me llamo Mariama Bari Fall que me lo saco! ¡Me saco la ESO! Es más por vagancia que por... siempre me decían: “¡es que si quieres, te lo sacas fácilmente!” y claro, cuando me ponía a estudiar, me lo sacaba muy fácilmente.”

Explica haber sido una buena estudiante y haber obtenido notables resultados cuando practicaba hábitos de estudio cotidianos, definiéndose como "vaga" o que "confiaba demasiado" cuando los resultados no eran los esperados, sin aludir a ningún otro factor de contexto o institucional que pudiese influir en su trayectoria académica. Su discurso parece haber incorporado la ideología meritocrática generalizada en las escuelas.

Entonces, en cuarto de ESO ya me dejé mucho llevar (...) me confié demasiado y ¡mira lo que paso! ¡Tuve que repetir!”

Al llegar a Francia fue matriculada en un curso anterior al que le correspondía e inicialmente asistió a un aula de refuerzo. Ella considera necesarias estas medidas y las acepta por su condición de recién llegada, insistiendo en que hacía lo mismo que el resto de alumnos pero con ayuda. En contraste, la repetición de cuarto de la ESO la vivió de forma muy distinta, rebajando sus aspiraciones académicas. En España no recibió apoyos específicos en el momento de su incorporación, ni es consciente de haber estado ubicada en grupos de nivel.

Finalmente, respecto a las relaciones con los iguales en la escuela observamos de nuevo discontinuidad. En Francia parece que consiguió cierta popularidad entre sus iguales y un alto grado de integración en el grupo, más allá de las horas que compartían en la escuela, siendo invitada a casa de otras chicas e incluso en el 
instituto francés, dónde sólo pasó un curso, la eligieron delegada. En cambio, su relato muestra aislamiento y dificultades para establecer, de nuevo, relaciones con los iguales en el instituto, rompiendo sus expectativas de recuperar las relaciones que había perdido al marcharse.

"Fui al instituto y el primer día me acuerdo que no hablaba con nadie... los reconocía pero... me deprimí mucho. Hasta llegaba a llorar porque... icon las ganas que tenia de volver y de encontrarme con todos y tal...! Porque los niños... siempre tienes la clase, cuando haces un cumpleaños invitas a toda la clase, entonces claro cuando volví y ya vi que no había esta conexión dije:”ijoder que triste!, y “iqué hago ahora!”.

En resumen, el relato de Mariama muestra los factores que condicionaron su trayectoria académica de continuidad educativa, aunque con un itinerario discontinuo y más largo. Su experiencia escolar fue positiva en Francia, no así en España, y allí contó con un contexto familiar y comunitario, apoyos más directos, modelos de referencia y una mayor vinculación social con los iguales y el profesorado en la escuela. Todos los elementos mencionados permitieron, primero, generar altas aspiraciones y, posteriormente, persistir ante las dificultades (Ver Anexo nº 1, Figura 1).

\section{IMPACTOS EN LAS CONDICIONES DE EMANCIPACIÓN Y EL PAPEL DE LOS VÍNCULOS Y REDES DE APOYO EN LA MOVILIDAD}

La movilidad de los chicos y chicas negroafricanos en etapas de escolarización obligatoria suele considerarse como una interrupción de las trayectorias académicas e incluso, desde una perspectiva escolar asimilacionista, una pérdida de la inversión realizada en su integración social. Para Mariama las relaciones sociales y las redes de apoyo fueron factores específicos clave de los que carecen otros jóvenes emigrantes sin vínculos con las migraciones internacionales. A continuación veremos el peso que tuvieron, añadiendo otra dimensión del estudio de cadenas y redes migratorias (Poeze, Dankyi y Mazzucato, 2017; Cuban, 2013), en la reconfiguración de sus aspiraciones, expectativas e identidades académicas. 
La movilidad supuso para Mariama un repetido esfuerzo de adaptación, que ella vinculaba al intento de incorporar nuevas relaciones y generar lazos de amistad. Refiriéndose constantemente a este aspecto, de su relato se desprende que establecer nuevas relaciones de confianza y reciprocidad fue fruto de su voluntad de "adaptarse" a los nuevos contextos. Cada movilidad fue acompañada de soledad y renuncia, no solo del núcleo familiar con el que residía, con cambios en hábitos y normas, sino también de los grupos de iguales. Un ejemplo de ello es como recordaba a su amiga de la infancia, amistad que no pudo mantener mientras estaba en Francia y no recuperó al volver a España. Sus relaciones fueron cada vez más intracomunitarias, basadas en las redes de relación y ayuda mutua de las que disponían sus padres, llegando a afirmar: "antes me relacionaba mucho con blancos, ahora me relaciono más con negros... que no sé por qué".

"Con las que salgo son fulas como yo y hablamos lo mismo (...). Por ejemplo, mi mejor amiga. Su madre y mi padre son casi mejores amigos también, yo y su hija, mejores amigas, y mi hermano con la hermana también."

Así pues, se puede identificar cierto cierre intraétnico local, aunque como argumenta Jiménez Sedano, la etnicidad no había sido ni era el criterio para estructurar su vida social, sino los lazos de parentesco real y metafórico, ante el fracaso de la escuela para generar pertenencia (Jiménez Sedano, 2012). Esto le proporcionó un grupo con pocos recursos, aunque sus lazos en la red transnacional se fortalecieron hasta el punto de permitir un nuevo proyecto propio de movilidad. Su red de parientes en Francia podría considerarse, así, una red bridging o puente, un acceso a otras identidades y a un grupo social con mayores recursos. Entre otros aprendizajes posibilitados por la movilidad, no hay que olvidar su competencia en seis idiomas — fula, castellano, catalán, francés, inglés y alemán-, aunque estos recursos no se apreciasen en su entorno escolar.

\subsection{Reconfiguración de aspiraciones y expectativas}

Mariama tenía unas aspiraciones muy claras. Pretendía aprovechar sus habilidades y se proponía poder trasladar este capital al ámbito laboral para ser traductora-intérprete profesional. En 
cambio, había cursado un CFGM en Gestión Administrativa, como consecuencia de la repetición en cuarto de ESO y la rebaja de sus expectativas:

"Antes de repetir, estaba "iyo quiero hacer bachillerato, el ciclo es para tontos, yo no hago ciclos, qué es eso! no sé qué, no sé cuántos..." y cuando repetí, luego ya... (...) al repetir me lo volví a pensar. Mejor no hago bachillerato porque si es tan duro y yo soy tan vaga..."

La orientación recibida entonces no tuvo en cuenta sus aspiraciones y no valoró los valiosos recursos adquiridos gracias a su origen familiar y a su trayectoria móvil. Esto contribuyó a desarrollar un sentimiento de incapacidad ("es tan duro y yo soy tan vaga"), que ha sido descrito en los análisis del impacto de la institución escolar en chicas de clase trabajadora y de minorías (Ajrouch, 2004; Phoenix, 2009; Archer-Banks y Behar-Horenstein, 2011). Aun así, cuando se planteó volver a Francia se apoyó en la red de parientes para buscar orientación educativa. Allí tampoco reconocieron su título postobligatorio pero a pesar de no poder convalidar los estudios españoles, el buen concepto de ella como estudiante que tenía allí su familia y las altas expectativas que ponían en ella, consiguieron que volviera a los planes iniciales y realizara el Bachillerato en Francia (terminándolo en el curso 2015-16) para poder acceder a la universidad. En definitiva, realizó una trayectoria más larga que a corto plazo no le ofreció oportunidades laborales, pero una trayectoria de persistencia, de "éxitos difíciles" (Archer, 2006; Mirza, 2008; Ponferrada, 2008) descritas entre las chicas de clase trabajadora y de minorías.

\subsection{Reconfiguración de identidades}

El relato de Mariama transmite una identidad dicotómica: o africana o europea, vinculadas respectivamente a tradición o modernidad, a la vez que ha experimentado distintos procesos de distanciamiento-acercamiento intracomunitarios. Ella explica cómo durante su infancia en España construía su identidad distanciándose de su propio grupo, hasta el punto de considerar que no contraería matrimonio "con un negro" o que ella se consideraba 
"más europea” que las "típicas negras". En cambio, como hemos visto, sus relaciones fueron cada vez más intracomunitarias. La única relación de noviazgo que tuvo fue con un chico negro nacido en Guinea. Ella relata que su opinión cambió, siguiendo las advertencias de su padre, para el que es importante que mantenga su identidad musulmana, especialmente siendo mujer.

"Si tú te casas con un blanco, como es un hombre y tú eres una mujer pues tú vas a ir más por donde va tu marido"[le dice su padre], pero mi hermano si se casase con una blanca no pasaría nada, porque él sería el que llevará la chica a la religión musulmana (...) pasa más que te cases con un blanco y seas más blanca tú también."

Pero también evoca una distancia cultural, considerando que una pareja mixta no funcionaría. Siente que no la podrían comprender ya que su mentalidad es también senegalesa. Así, aunque haya nacido en España y tenga la nacionalidad española, atribuye al hecho de que sus padres les hayan "involucrado" la emergencia de una identidad mixta, que percibe como irreconciliable. Sin embargo, se distingue de una definición tradicional de "buena musulmana" y afirma que nunca llevaría pañuelo, una expresión identitaria que parece contraponerse al proyecto de emancipación como "mujer europea-moderna" que pretende emprender.

"Yo soy más europea... Además llevar pañuelo supone, quiere decir que ya... (...) te tienes que involucrar mucho en la religión (...) Allí ya eres musulmana $100 \%$... Yo no lo llevaría. No porqué me prohíba salir de fiesta, porque igualmente aunque no saliera de fiesta tampoco llevaría el pañuelo, no me gusta, lo veo bonito pero...".

Para ella "ser más europea" significa alejarse del cumplimiento de las normas y el control sobre el cuerpo, la sexualidad y el comportamiento considerado "honorable" en la definición tradicional de mujer musulmana que ella misma define. Intenta negociar y resistir al modelo de género-edad intracomunitario, que se materializa en un mayor control de las jóvenes (en su caso, mayor que el que recibe su hermano menor) que encarnan la honorabilidad familiar, a menudo de forma más estricta que sus pares en origen. De hecho, considera que su padre tiene una actitud flexible a la que ella puede responder u oponerse, y esos mensajes no han supuesto menores expectativas educativas hacia ella, sino lo contrario, porque 
como hermana mayor debe dar ejemplo. Así, explica que su padre nunca ha impuesto a los hijos el ayuno del Ramadán, aunque ella sabe que sería su deseo. Aun sí, también le ha ocultado información, como no decirle que tenía una relación de noviazgo.

En paralelo, se ha producido un relajamiento y una flexibilización de los roles de género tradicionales en el reparto de las tareas domésticas. Aunque Mariama se atribuye este trabajo, según ella su padre participa en ellas mucho más que su propio hermano y, en sus propias palabras, la "ayuda". Pero su proyecto emancipador parece tener un modelo en Francia, su tía, una "mujer africana moderna”.

"Yo, mi tía allí pues muy moderna ella, muy... se relaciona mucho con los padres de... porque aquí siempre los blancos, a ver, se relacionan mucho con los padres de los hijos cuando van al cole. Pero aquí... yo no he visto casi ninguna negra que vaya y a lo mejor se relacione con los padres de... van a buscar a su hijo al cole y adiós, para casa y... cerradas, y no salen y no... Yo no sé si es porque el marido no les permite o si ellas mismas no quieren, pero yo creo que deberían hacerlo".

Finalmente, es importante destacar que su discurso revela una cierta conciencia de la racialización, aunque su análisis está impregnado de la forma en la que se concreta la estratificación étnica en el contexto español y europeo, asociados a la extranjería. En su relato siempre explicita los orígenes y la pertenencia étnica de la persona de la que habla (si es gitano, rumana, brasileña...) y el color (si es negro/a o no). Usa la nacionalidad como sinónimo de origen familiar, y el color para distinguir a "autóctonos" —nacidos en España, asociados a ser blancos-de "negros", independientemente de su lugar de nacimiento y nacionalidad. Su necesidad de precisar contrasta con los relatos de las chicas negroafricanas sin experiencias de movilidad, probablemente porque el contexto francés es mucho menos "ciego" a la negritud.

\section{A MODO DE CONCLUSIÓN}

El caso de Mariama nos permite romper los principales tópicos sobre la percepción de la movilidad de los migrantes de origen negroafricano y situarla en las estrategias de los jóvenes europeos de los países del sur ante la falta de expectativas. Su análisis 
también contribuye a reconstruir y comprender la lógica de las estrategias de mantenimiento del proyecto migratorio por parte de las familias negroafricanas en Europa. Más allá de representaciones etnocéntricas que parecen limitar las decisiones de las familias respecto a la movilidad de sus hijas al objetivo de mantenerlas en la tradición, se identifican nuevas nociones de logro y éxito vinculadas al proceso de emancipación tanto de los hijos como de las hijas, en las que el acceso a la educación superior adquiere un papel central. Muchas familias proyectan altas aspiraciones educativas sobre sus hijos, independientemente del género, y apoyan proyectos emancipadores flexibilizando, para las segundas generaciones, las nociones de feminidad y masculinidad tradicionales y los comportamientos asociados a ellas. Estar centrado en los estudios permite desarrollar un rol aceptado por la comunidad que no amenaza el prestigio familiar, conjugar la promoción de estos "nuevos" caminos y acompañar las trayectorias correspondientes. Estas transformaciones subyacen en las aspiraciones y capacidades (De Haas, 2014) de Mariama para desarrollar su proyecto migratorio, consolidado por sus experiencias anteriores de movilidad.

Dentro del "éxodo de la juventud española" permanecen invisibles los hijos de inmigrantes que, como otros jóvenes cualificados, no consiguen encontrar un valor de cambio a sus titulaciones en el mercado laboral, además de tener que afrontar discriminaciones específicas y bien documentadas. Sin embargo, aunque ellos no forman parte de las clases medias en las que se concibe la movilidad como oportunidad y aprendizaje en sí misma, cuentan con un valioso capital migratorio, en términos de capital cultural (lenguas y habitus migratorio familiar) y social (red transnacional con recursos movilizables) en sus procesos de emancipación, retomando y actualizando los proyectos iniciales de los padres en los países más ricos de Europa.

\section{BIBLIOGRAFÍA}

Abajo, E. y CARRAsco, S. (2004): Experiencias y trayectorias de éxito escolar de gitanas y gitanos en España. Madrid: CIDE - Instituto de la Mujer.

Ajrouch, K. J. (2004): «Gender, Race and Symbolic Boundaries: Contested Spaces of Identity among Arab American Adolescents». Sociological Perspectives 47 (4): 371-91. 
AlbA, R. (2005): «Bright vs. Blurred Boundaries: Second-Generation Assimilation and Exclusion in France, Germany and the United States». Ethnic and Racial Studies 28 (1): 20-49.

Anthias, F. (2007): «Ethnic Ties: Social Capital and the Question of Mobilisability». Sociological Review 55 (4): 788-805.

Archer-Banks, D. and Behar-Horenstein, L. (2011): «Ogbu Revisited: Unpacking High-achieving African American Girls' High School Experiences». Urban Education 47 (1): 198-223.

Bertran, M.; Ponferrada, M. and Pàmies, J. (2016): «Gender, Family Negotiations and Academic Success of Young Moroccan Women in Spain». Race, Ethnicity and Education 18 (1): 1-21.

Bledsoe, C. and Sow, P. (2007): «High Fertility Gambians in Low Fertility Spain: The Dynamics of Child Accumulation across Transnational Space». Demographic Research 16 (12): 375-412.

Bledsoe, C. and Sow, P. (2011): «Back to Africa: Second Chances for the Children of West African Immigrants». Journal of Marriage and Family 73 (4): 747-62.

Bonilla-Silva, E. (2006): Racism Withouth Racists. Color-Blind Racism and the Persistence of Racial Inequality in the United States. Second ed. Oxford: Rowman \& Littlefield Publishers, INC.

Carrasco, S. y Laia N. (2015): "Migración, movilidad y experiencia escolar. Jóvenes con trayectorias de movilidad en un sistema normalizador de la inmovilidad». VIII Congreso sobre Migraciones Internacionales en España, Granada.

Cuban, S. (2013): Deskilling Migrant Women in the Global Care Industry. Basingstoke: Palgrave MacMillan.

De HaAs, H. (2014): «Migration Theory: Quo Vadis?» IMI Working Paper Series, 100. Oxford: International Migration Institute.

Domingo, A. y Blanes, A. (2016): "La nueva emigración española: ¿una generación perdida?» Panorama Social n 23. Primer semestre: 157-78.

Domingo, A.; Sabate, A. y Ortega, E. (2014): «¿Migración neohispánica? El impacto de la crisis económica en la emigración española». EMPIRIA. Revista de metodología de ciencias sociales $\mathrm{n}^{\circ} 29$, septiembre-diciembre: 39-66.

FARJAS, A. (2002): "La escolarización en Gambia» Revista española de educación comparada 8: 227-59.

GaBrielli, L. (2010): Los procesos de socialización de los hijos e hijas de familias senegalesas y gambianas en Cataluña. Barcelona: Fundació Jaume Bofill.

Glick Schiller, N. and Salazar, N. B. (2013): «Regimes of Mobility across the Globe». Journal of Ethnic and Migration 39 (2): 183-200.

GoldBERG, A. (2010): «Hijos de familias migrantes senegalesas residentes en Cataluña: un abordaje antropológico alrededor de sus procesos de socialización». AIBR, Revista de Antropología Iberoamericana Vol. 5, No 2, 319-356. 
Gutekunst, M. et al. (eds.) (2016): Bounded Mobilities. Ethnographic Perspectives on Social Hierarchies and Global Inequalities. Bielefeld: Transcript-Verlag.

JABARdo, M. (2006): Senegaleses en España. Conexiones entre origen y destino. Documentos del Observatorio permanente de la inmigración, núm.11. Madrid: Secretaría General de Inmigración y Emigración.

JimÉnEZ, M y VAcchiano, F. (2011): «De dependientes a protagonistas. Los menores como sujetos migratorios». Pp.495-512 en El Río Bravo Mediterráneo: Las regiones fronterizas en la época de la globalización. Barcelona: Ed. Bellaterra.

JimÉnez SEDANo, L. (2012): "On the irrelevance of ethnicity in children's organization of their social world». Childhood 19(3), 375-388.

Kandel, W. and Massey, D. (2002): The culture of Mexican migration: A theoretical and empirical analysis. Social forces 80 (3) 981-1004.

Kaplan Marcusán, A. (1998): De Senegambia a Cataluña: Procesos de aculturación e integración social. Barcelona: Fundació «La Caixa».

López CABEzAS, J. M. (2005): «Racismo y pensamiento moderno: el ejemplo de la invención de los camitas y los subsaharianos» Pp.5563 en $O$ racismo ontem e hoje. Estados, poderes e identidades na África Subsahariana, Actas do VII Colóquio Internacional Estados, Poderes e Identidades na África Subsariana, Centro de Estudos Africanos, Universidade do Porto.

Mac an Ghaill, M. (1994): The Making of Men: Masculinities, Sexualities and Schooling. Buckingham; Philadelphia: Open University Press.

Masdeu, I. y SAIZ, A. (2017): «Género, movilidad e intersecciones generacionales en el espacio transnacional chino», Revista Española de Sociología 26 (3) (2017), 385-397.

Merla, L. (2014): «La circulación de cuidados en las familias transnacionales» Revista CIDOB d'afers Internacionals 106-107, 85-104.

Mirza, H. S. (2008): Race, Gender and Educational Desire: Why Black Women Succeed and Fail. London and New York: Routledge.

NARciso, L. (2010): «Anàlisi de la producció científica sobre la immigració negroafricana a Espanya i Catalunya» Quaderns-e 15 (2), 76-95.

NAPles, N. (2003): Feminism and Method: Ethnography, Discourse Analysis and Activist Research.New York and London: Routledge.

NowickA, M. (2015): «Habitus: Its transformation and transfer through cultural encounters in migration»Pp.93-110 in Bourdieu, Habitus and Social Research. Palgrave Macmillan UK.

NYíRI, P. (2014): "Training for Transnationalism: Chinese Children in Hungary». Ethnic and Racial Studies 37 (7): 1253-1263.

Ogbu, J. (1981): «School Ethnography: A Multilevel Approach». Anthropology \& Education Quarterly 12 (1): 3-29.

Phoenix, A. (2009): «De-Colonising Practices : Negotiating Narratives from Racialised and Gendered Experiences of Education». Race Ethnicity and Education 44 (March): 1-22. 
Poeze, M.; Ernestina, K. D. and Mazzucato, V. (2017): «Navigating Transnational Childcare Relationships: Migrant Parents and their Children's Caregivers in the Origin Country». Global Networks 17 (1): 111-29.

Ponferrada, M. (2008): «Exitos dificiles y fracasos invisibles: aspiraciones y trayectorias de jóvenes de clase trabajadora y de origen inmigrante en la periferia de Barcelona». X Coloquio Internacinal de Geocritica, 1-13.

Putnam, R. D. (2000): Bowling Alone: The Collapse and Revival of American Community. Simon \& Schuster.

RiEssman, C. K. (2008): Narrative Methods for the Human Sciences. CA, USA: SAGE Publications.

SANTOS, A. (2013): «Fuga de cerebros y crisis en España: los jóvenes en el punto de mira de los discursos empresariales». Areas. Revista Internacional de Ciencias Sociales 32: 125-37.

Sow, P. (2007): «Diásporas africanas y mundialización: de la representación histórica a la toma de conciencia». Pp.135-52 en África En Diáspora: movimientos de población y politicas estatales. Barcelona: Bellaterra.

Suárez-Orozco, C. and Suárez-Orozco, M. (2003): La Infancia de La Inmigración. Madrid: Ediciones Morata.

Wall, K. and Bolzman, C. (2013): «Mapping the New Plurality of Transnational Families. A life course perspective» Pp. 68-96 in Transnational families, migration and the circulation of care. Understanding mobility and absence in family life. New York: Routledge.

Waters, M., Van C. Tran, P. K. and Mollenkopf, J. H. (2010): «Segmented Assimilation Revisited: Types of Acculturation and Socioeconomic Mobility in Young Adulthood». Ethnic and Racial Studies 33 (7): 1168-93.

WeEninK, D. (2008): «Cosmopolitanism as a Form of Capital: Parents Preparing Their Children for a Globalizing World». Sociology 42 (6): 1089-1106.

Wimmer, A. and Glick Schiller, N. (2003): «Methodological Nationalism, the Social Sciences and the Study of Migration: An Essay in Historical Epistemology». International Migration Review 37 (3): 576-610.

Yosso, T. (2005): "Whose Culture Has Capital? A Critical Race Theory Discussion of Community Cultural Wealth». Race Ethnicity and Education 8 (1): 69-91.

Zhou, M. (2005): «Ethnicity as Social Capital: Community-Based Institutions and Embedded Networks of Social Relations». Pp. 123-31 in Ethnicity, Social Mobility, and Public Policy. Cambridge University Press. 


\section{ANEXO No 1}

\section{TABLA 1}

\section{ÍNDICE DE SUCESOS Y ETAPAS EN LA VIDA DE MARIAMA}

\begin{tabular}{|c|c|c|}
\hline Año & Edad & Suceso \\
\hline 1994 & 0 & Nace septiembre de 1994 en un municipio de la Provincia de Barcelona. \\
\hline 1995 & 1 & Inicio jardín de infancia público en el mismo municipio (centro). \\
\hline 1997 & 3 & Inicio educación infantil (P3) (escuela pública, centro) (Curso 1997/98). \\
\hline 1998 & 4 & Nacimiento hermano. \\
\hline 2000 & 5 & $\begin{array}{l}\text { Inicio educación primaria en misma escuela (curso 2000/01), dónde continua } \\
\text { hasta } 3^{\circ} \text { Primaria (8 años, curso 2002/03). }\end{array}$ \\
\hline 2003 & $8 / 9$ & $\begin{array}{l}\text { Va a vivir a Francia (1) familia paterna (pareja+3 hijos). Se incorpora a una escuela } \\
\text { pública de primaria (curso 2003/04, repitiendo: CE1) y termina la primaria (École } \\
\text { élémentaire), (curso 2006/07). }\end{array}$ \\
\hline $2006 / 07$ & 12 & $\begin{array}{l}\text { Cambio de residencia y núcleo familiar (2): va a vivir con una prima (pareja y dos } \\
\text { hijos). Inicia educación secundaria (Collège) en el nuevo barrio. }\end{array}$ \\
\hline 2008 & 13 & $\begin{array}{l}\text { Regresa a España (3), al mismo municipio y se escolariza en } 2^{\circ} \text { de la ESO (curso } \\
\text { 2008/09), en un instituto del centro (el que correspondía a la escuela primaria } \\
\text { dónde había estado).Empieza ocio nocturno. }\end{array}$ \\
\hline $2009 / 10$ & 15 & Trabaja en verano dos meses en un hotel (en el que trabaja su padre). \\
\hline $2010 / 11$ & 16 & Inicia relación noviazgo con un chico (Origen Guinea, generación 1’5). \\
\hline $2011 / 12$ & 17 & $\begin{array}{l}\text { Repite } 4^{\circ} \text { ESO (curso 2011-12) y termina graduando. Separación de sus padres } \\
\text { (junio 2012). }\end{array}$ \\
\hline $2012 / 13$ & 18 & Inicia CFGM gestión administrativa. \\
\hline $2013 / 14$ & 19 & $\begin{array}{l}\text { Termina CFGM y planifica viajar Francia. Termina su relación de noviazgo. Realiza } \\
\text { una estancia en Francia (casa de sus tíos) de vacaciones en semana santa y su } \\
\text { hermano se queda allí. Viaja a Francia (4) (junio 2014). }\end{array}$ \\
\hline 2016 & 21 & $\begin{array}{l}\text { Reside en Francia con otros familiares paternos y estudia des del curso 2014/15 } \\
\text { Bachillerato (Lycée), que tiene previsto terminar este año. }\end{array}$ \\
\hline
\end{tabular}

Fuente: elaboración propia, a través de la información obtenida en las sucesivas entrevistas realizadas. 
FIgURA 1

RESUMEN DE LOS FACTORES DE VINCULACIÓN ACADÉMICA Y SOCIAL IDENTIFICADOS EN LA TRAYECTORIA DE MARIAMA

APOYO FAMILIAR Y COMUNITARIO:

- Mensages de aprovechamiento escolar y

apoyo indirecto (padres)

- Apoyo escolar directo (primas)

- Estilo parental proescolar (control y

supervisión) en Francia.

- Referentes positivos y modelos de éxito en Francia.

EXPERIENCIA ESCOLAR POSITIVA EN FRANCIA:

- Experiencia académica no segregada y alta vinculación social

Figuras clave de apoyo entre el profesorado.

- Relación positiva con iguales, más allá de la escuela.

Fuente: elaboración propia. 